\title{
Effect of F/M Ratio on the Performance of Sequencing Batch Reactor for Dairy Wastewater Treatment
}

\author{
Harshada Vallabha Vibhhute ${ }^{1 *}$, Bharat Ingavale ${ }^{1^{* * *}}$
}

\author{
${ }^{1}$ Department of Environmental Engineering, K.I.T.’s College of Engineering (Autonomous), Kolhapur, INDIA \\ *Corresponding Author: harshadavibhute@gmail.com \\ ***Corresponding Author: bharatingavale@gmail.com
}

Citation: Vibhhute, H. V., \& Ingavale, B. (2020). Effect of F/M Ratio on the Performance of Sequencing Batch Reactor for Dairy Wastewater Treatment. Aquademia, 4(2), ep20021. https://doi.org/10.29333/aquademia/8422

\section{ARTICLE INFO}

Received: 15 Jun. 2020

Accepted: 16 Jul. 2020

\begin{abstract}
Indian economy has huge contribution of dairy industry. About one fourth of nation's income is contributed by dairy. Milk processing involves various operations starting from receiving point to disposal end. This whole process demands fresh water leading to wastewater generation and this quantity is highest amongst all industries. Dairy wastewater is composed of organic matter, nutrients, suspended \& dissolved solids and high COD, BOD. So it becomes necessary to remove the pollution load before its disposal. Some advanced treatments like SBR, gas stripping, surface filtration show better results and are effective than conventional treatments. In this study, SBR process was used to treat dairy wastewater. SBR process has flexibility, minimal footprint and it conducts all operations like equalization, primary clarification, biological treatment and secondary settling in a single reactor. Time phased Fill and draw type lab scale SBR model was operated with 12 liter total volume and 10 liter working volume. Before loading dairy wastewater to the reactor, loading of sewage was done for acclimatization of microorganisms. Dairy wastewater was collected from equalization tank of an Effluent Treatment Plant of dairy industry. It was analysed for various parameters for 15 days to know the variations in characteristics. For the treatment of dairy wastewater reactor was operated under varying MLSS from 6000 to $8000 \mathrm{mg} / \mathrm{L}$ thereby under varying F/M ratio and named as phase 1, phase 2, and phase 3 with 20\% Volume Exchange Ratio. Total cycle time provided was 6 hour in which fill was instantaneous, aeration for 5 hour 30 minutes, settling for 25 minutes and 5 minute decant. By keeping all the remaining parameters constant, only F/M ratio was varied. Maximum removal efficiencies for parameters like COD, BOD, TDS, and TSS were determined for each phase. For phase 1, 2 and 3 maximum removal efficiencies were achieved at $\mathrm{F} / \mathrm{M} \mathrm{0.16,0.14}$ and 0.13 per day respectively. But among all three phases, $3^{\text {rd }}$ phase gave maximum removal efficiency at F/M 0.13. Hence it was concluded that SBR performs better at higher MLSS concentration or at lower F/M ratio in order to achieve disposal standards.
\end{abstract}

Keywords: dairy wastewater treatment, sequencing batch reactor (SBR), F/M ratio

\section{INTRODUCTION}

Milk and milk products play important roles in our day to day life and hence Dairy industries too. India is a country where one fourth of nation's income is contributed by dairy. In developing country like India there is urbanization and industrialization which increases the growth of dairy industry and its allied industries ${ }^{1}$. There are different operations which take place in dairy industry such as, receiving station receives milk, then milk is weighed, tested and then it is sent for Pasteurization, Cheese making, Butter making, ice-cream, milk powder, condensed milk, yoghurt, panner, etc. Pasteurization is nothing but heating the milk at $62^{\circ} \mathrm{C}$ for 30 minutes or at $71^{\circ} \mathrm{C}$ for 15 minutes (Shete \& Shinkar, 2013). Further milk is cooled down and it is packed into polythene bags or bottles.
Large amount of fresh water is required to carry out these all operations. For processing of 1 liter milk, about 1.6 liter of water is required (Sutar et al., 2015). Apart from this, water is required to wash out the empty cans, bottles, polythene bags, apparatus, for gardening and extraordinary incidental purposes. Now water gets converted into wastewater after its use. This wastewater brings many things along with it like, suspended and dissolved solids, organic and inorganic matter, various nutrients, plastic bags, chemicals, and is with high COD and BOD (Mehrotra \& Trivedi, 2016). So disposal of such a contaminated wastewater without any treatment is not possible and not allowed. It may harm natural environment very badly.

To treat wastewater produced in the dairy, various conventional and advanced treatments are used. These all treatments are mainly classified into three parts that is primary, secondary, tertiary. Primary treatment removes large 
floatable materials, oil and grease, whereas secondary treatment is a biological treatment and removes organic and inorganic matter from the wastewater. Third and the last is tertiary treatment which mostly not provided as it is not economical but improves water quality. There are some conventional treatments like anaerobic sludge blanket reactor, trickling filter, aerated lagoons, wastewater stabilization pond which are used for treatments, but because of some limitations advanced treatments are preferred over it (David, 2016). Surface filtration, ion exchange, membrane filtration, reverse osmosis, gas stripping, sequential batch reactor are advanced treatments used to treat every kind of wastewater. Sequential Batch Reactor is one of the effective processes and can be used for domestic and industrial wastewater treatment.

For the present study, SBR process was used to treat dairy wastewater. It is a modification of activated sludge process. It is a fill and draw type reactor which works in time phased system (Gürtekin, 2014). Different processes like equalization, biological treatment and secondary clarification are carried out in a single tank of SBR, which makes it as an economical process (Mohseni-Bandpi \& Bazari, 2004). Mainly five phases take place sequentially one after other, Fill, React, Settle, Draw, Idle in SBR. Fill is the phase in which, wastewater is loaded in to the reactor, aeration is provided in react phase. In settle phase aeration is stopped and sludge is allowed to settle down and further supernatant is removed in decant phase. In this study, MLSS was varied by keeping all the parameters constant to treat dairy wastewater by using SBR. Thus, effect of varying MLSS and thereby varying F/M ratio was analyzed for the treatment of dairy wastewater by using SBR process.

\section{MATERIALS AND METHODOLOGY}

Dairy wastewater was collected from a dairy industry's effluent treatment plant. As SBR is considered to be secondary treatment process, wastewater was collected from equalization tank after primary treatment of screening and fat removal. Also, to come over the variations in quality of wastewater with respect to time, it was collected from equalization tank of ETP.

\section{Reactor Setup}

Acrylic sheet was used to prepare the reactor with length $20 \mathrm{~cm}$, width $20 \mathrm{~cm}$ and height $30 \mathrm{~cm}$. Total volume of the reactor was 12 liter and working volume was 10 liter. Diffused aerators were used for aeration purpose. For initial development of biomass in the reactor, MLSS from sewage treatment plant was loaded in the reactor.

\section{Operation of Reactor}

\section{Wastewater application to reactor}

Initially sewage was applied to the reactor for the development of microorganisms. The reactor was operated with sewage as wastewater for 10 days duration. Primary analysis of dairy wastewater was carried out to understand the variations in its quality. Parameters like $\mathrm{pH}, \mathrm{COD}$, BOD, TDS, and TSS were analyzed for this primary treated dairy wastewater.

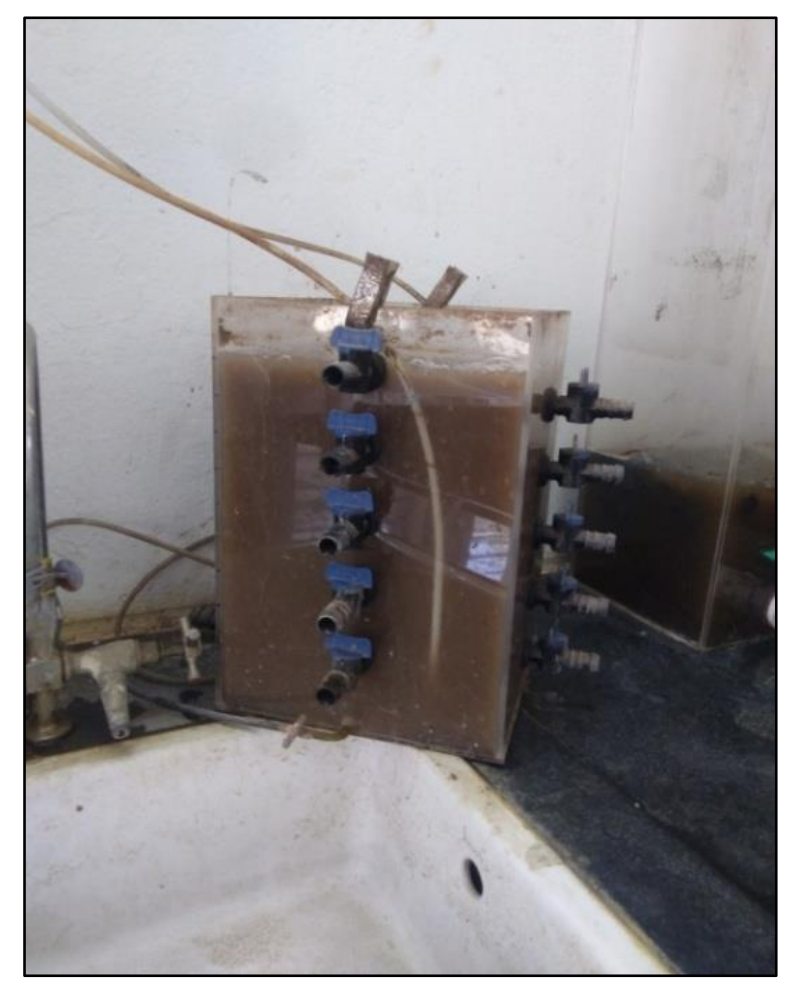

Figure 1. Reactor Set up

After development of biomass in reactor, dairy wastewater was fed stepwise in combination with sewage. The composition of dairy wastewater in this mixture was increased from $25 \%$ to $100 \%$ to avoid shock loading and acclimatization of microorganisms.

\section{Treatment of Dairy Wastewater}

The main objective of this study was to determine the effect of F/M ratio on performance of SBR while treating dairy wastewater. So in order to achieve this objective, three phases of operation of reactor were taken into consideration. These three phases were operated under three MLSS concentrations ranging from $6000 \mathrm{mg} / \mathrm{L}$ (Phase 1), $7000 \mathrm{mg} / \mathrm{L}$ (Phase 2) and $8000 \mathrm{mg} / \mathrm{L}$ (Phase 3). Total cycle time period provided was 6 hour. Fill phase was instantaneous; aeration was provided for 5 hour 25 minutes, settling was done in 30 minutes and decant time was 5 minute. As MLSS changes F/M ratio also get changed. All three phases with MLSS $6000 \mathrm{mg} / \mathrm{L}, 7000 \mathrm{mg} / \mathrm{L}$, and $8000 \mathrm{mg} / \mathrm{L}$ were operated for 6 hour cycle time, to analyze parameters like COD, BOD, TDS, TSS of dairy wastewater. Phase 1 and 2 were operated for 10 days and inlet and outlet parameters were recorded whereas Phase 3 was operated for 5 days. Decant percentage was decided as $20 \%$ of total volume of the reactor for operation of all phases.

\section{RESULT AND DISCUSSION}

The inlet and outlet parameters like $\mathrm{pH}$, COD, BOD, TDS, TSS of dairy wastewater were analysed by varying MLSS thereby varying $\mathrm{F} / \mathrm{M}$ ratio. 


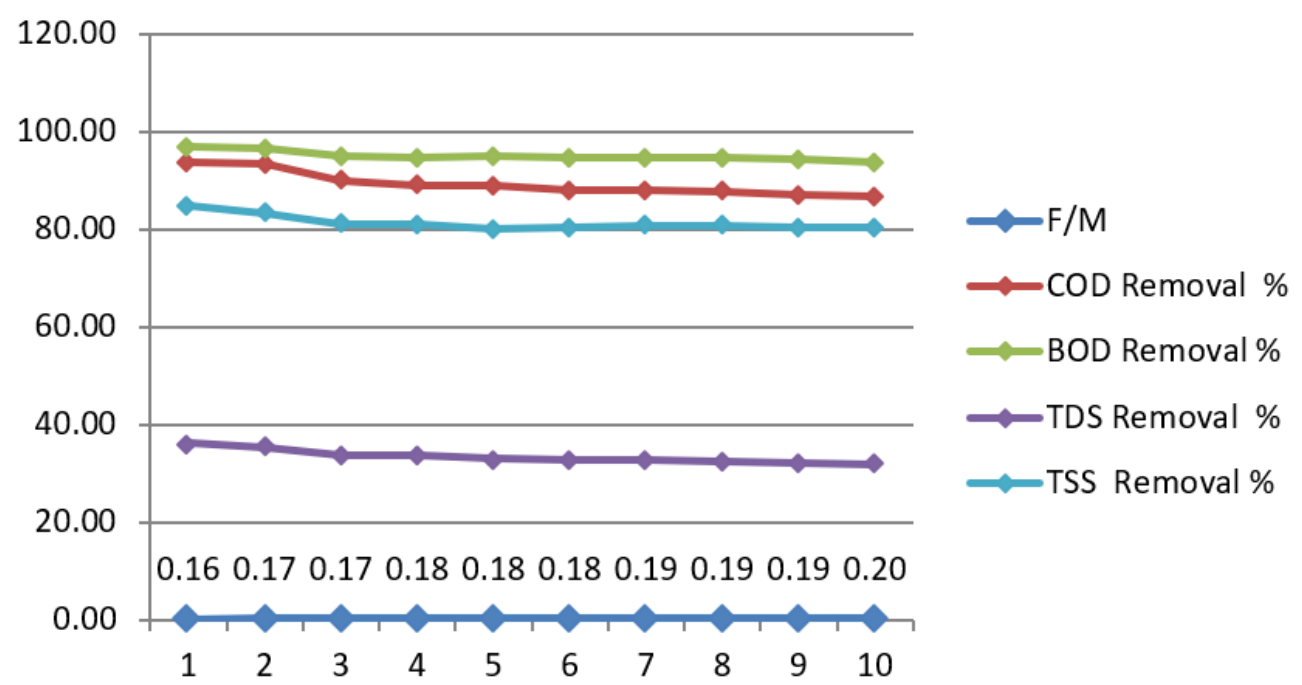

Figure 2. \% Removal Efficiencies for Phase 1
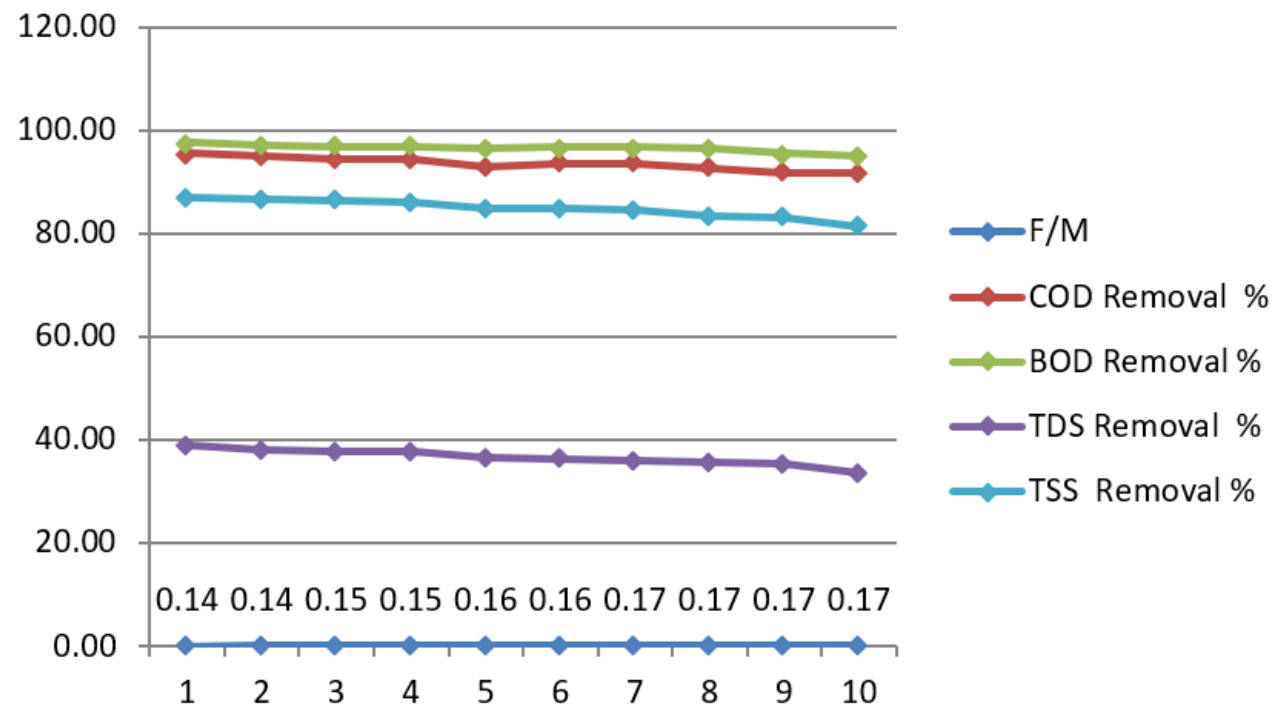

Figure 3. \% Removal Efficiencies for Phase 2

\section{$1^{\text {st }}$ Phase of Operation of Reactor}

$1^{\text {st }}$ phase of study was operated for 10 days duration with MLSS concentration maintained near to $6000 \mathrm{mg} / \mathrm{L}$. With daily wasting of sludge from reactor MLSS concentration observed from $5800 \mathrm{mg} / \mathrm{L}$ to $6687 \mathrm{mg} / \mathrm{L}$ for Phase 1. F/M ratio calculated with these MLSS concentrations were observed to vary from 0.16 to 0.20 per day.

After treatment $\mathrm{pH}$ of effluent were observed in range of 8.04 to 8.25 . COD and BOD of treated wastewater were observed to be varied from 100 to $320 \mathrm{mg} / \mathrm{L}$ and 38 to $90 \mathrm{mg} / \mathrm{L}$ respectively. TDS and TSS were observed to vary from 504 to $931 \mathrm{mg} / \mathrm{L}$ and 71 to $132 \mathrm{mg} / \mathrm{L}$ respectively.

For this phase, maximum removal efficiencies were observed at $0.16 \mathrm{~F} / \mathrm{M}$ per day. These were $93.75 \%$, 96.83\%, $36.09 \%$, $84.84 \%$ for parameters COD, BOD, TDS, TSS respectively. Average concentrations for treated wastewater of the parameters COD, BOD, TDS, TSS were observed to be 216 $\mathrm{mg} / \mathrm{L}, 69.3 \mathrm{mg} / \mathrm{L}, 710.6 \mathrm{mg} / \mathrm{L}, 102.3 \mathrm{mg} / \mathrm{L}$ and $812.9 \mathrm{mg} / \mathrm{L}$ respectively. These average concentration values of effluent comply with disposal standards provided by CPCB except for BOD.

\section{$2^{\text {nd }}$ Phase of Operation of Reactor}

$2^{\text {nd }}$ phase of study was operated for 10 days duration with MLSS concentration maintained near to $7000 \mathrm{mg} / \mathrm{L}$. With daily wasting of sludge from reactor MLSS concentration observed from $6895 \mathrm{mg} / \mathrm{L}$ to $7228 \mathrm{mg} / \mathrm{L}$ for this Phase 2. F/M ratio calculated with these MLSS concentrations were observed to vary from 0.14 to 0.17 per day.

After treatment $\mathrm{pH}$ of effluent were observed in range of 8.04 to 8.65. COD and BOD of treated wastewater were observed to be varied from 80 to $200 \mathrm{mg} / \mathrm{L}$ and 30 to $74 \mathrm{mg} / \mathrm{L}$ respectively. TDS and TSS were observed to vary from 480 to $850 \mathrm{mg} / \mathrm{L}$ and 43 to $122 \mathrm{mg} / \mathrm{L}$ respectively.

For this phase, maximum removal efficiencies were observed at $0.14 \mathrm{~F} / \mathrm{M}$ per day. These were $95.56 \%$, 97.60\%, $38.93 \%$, 87.11\%, for parameters COD, BOD, TDS, TSS respectively. Average concentrations for treated wastewater of the parameters COD, BOD, TDS, TSS were observed to be 132 $\mathrm{mg} / \mathrm{L}, 49 \mathrm{mg} / \mathrm{L}, 714 \mathrm{mg} / \mathrm{L}, 84.3 \mathrm{mg} / \mathrm{L}$ and $798.6 \mathrm{mg} / \mathrm{L}$ respectively. These average concentration values of effluent comply with disposal standards provided by CPCB except for BOD. 


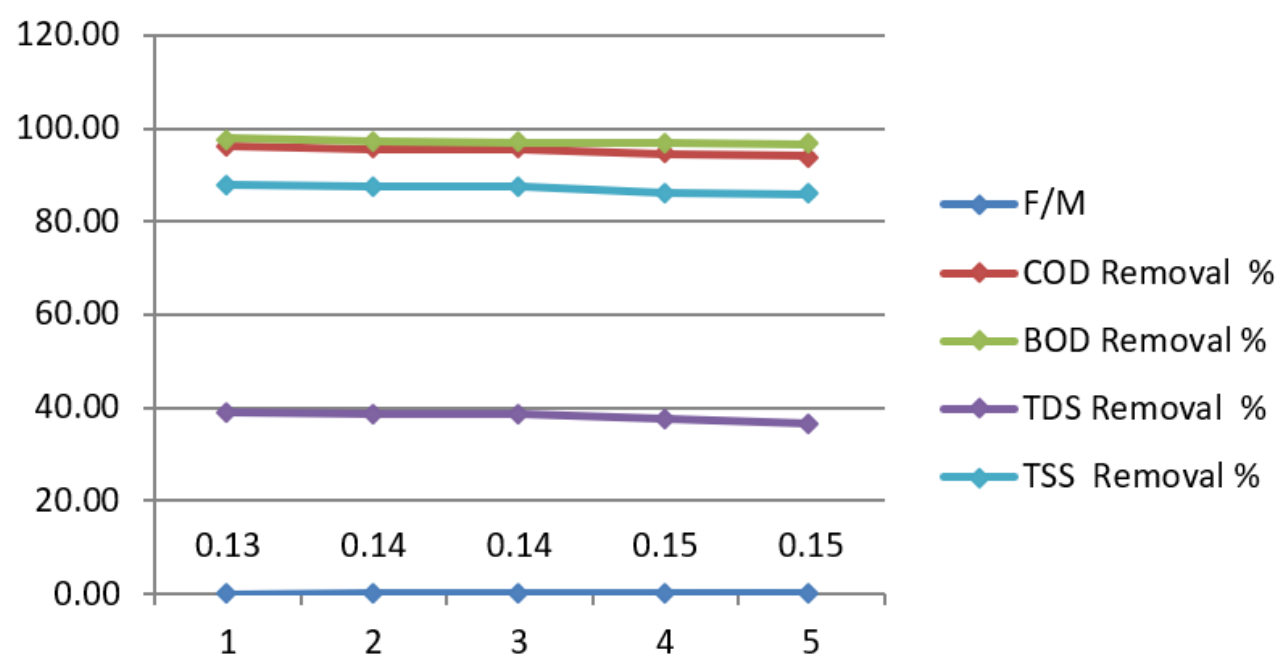

Figure 4. \% Removal Efficiencies for Phase 3

Table 1. Average Removal Efficiencies

\begin{tabular}{ccccc}
\hline \multirow{2}{*}{ MLSS (mg/L) } & \multicolumn{4}{c}{ Average \% Removal } \\
\cline { 2 - 5 } & COD Removal \% & BOD Removal \% & TDS Removal \% & TSS Removal \% \\
\hline 6000 & 89.29 & 95.01 & 33.36 & 81.31 \\
\hline 7000 & 93.59 & 96.54 & 36.62 & 84.88 \\
\hline 8000 & 95.18 & 97.08 & 38.10 & 86.98 \\
\hline
\end{tabular}

\section{$3^{\text {rd }}$ Phase of Operation of Reactor}

$3^{\text {rd }}$ phase of study was operated for 5 days duration with MLSS concentration maintained near to $8000 \mathrm{mg} / \mathrm{L}$. With daily wasting of sludge from reactor MLSS concentration observed from $7763 \mathrm{mg} / \mathrm{L}$ to $7886 \mathrm{mg} / \mathrm{L}$ for this Phase 3. F/M ratio calculated with these MLSS concentrations were observed to vary from 0.13 to 0.15 per day.

After treatment $\mathrm{pH}$ of effluent were observed in range of 8.03 to 8.65. COD and BOD of treated wastewater were observed to be varied from 60 to $120 \mathrm{mg} / \mathrm{L}$ and 27 to $53 \mathrm{mg} / \mathrm{L}$ respectively. TDS and TSS were observed to vary from 580 to $863 \mathrm{mg} / \mathrm{L}$ and 45 to $81 \mathrm{mg} / \mathrm{L}$ respectively.

For this phase, maximum removal efficiencies were observed at $0.13 \mathrm{~F} / \mathrm{M}$ per day. These were $96.25 \%$, 97.84\%, $38.95 \%$, $87.97 \%$, for parameters COD, BOD, TDS, TSS respectively. Average concentrations for treated wastewater of the parameters COD, BOD, TDS, TSS were observed to be 92mg/L, $41 \mathrm{mg} / \mathrm{L}, 707.6 \mathrm{mg} / \mathrm{L}, 66.2 \mathrm{mg} / \mathrm{L}$ and $773.8 \mathrm{mg} / \mathrm{L}$ respectively. These average concentration values of effluent comply with disposal standards provided by CPCB except for BOD.

\section{Average \% Removal Efficiencies of Three Phases}

Comparing the removal efficiencies for various $\mathrm{F} / \mathrm{M}$ ratios for all phases of SBR reactor operation, it was observed that maximum removal efficiencies were observed for $\mathrm{F} / \mathrm{M}$ ratio of 0.13 per day. Further, removal efficiencies of these parameters can be increased by increase in MLSS concentration and thereby decrease in F/M ratio, increase in react time, decrease in volume exchange ratio.

\section{CONCLUSIONS}

1. Using SBR, treatment of dairy wastewater is done to analyze the parameters like COD, BOD, TDS, and TSS by varying MLSS concentrations and thereby varying $\mathrm{F} / \mathrm{M}$ ratio.

2. In $1^{\text {st }}$ phase maximum removal efficiencies observed were $93.75 \%, 96.83 \%, 36.09 \%$, 84.84\% for F/M ratio 0.16 for parameters COD, BOD, TDS, TSS.

3. In $2^{\text {nd }}$ phase maximum removal efficiencies observed were $95.56 \%$, 97.60\%, 38.93\%, $87.11 \%$ for $\mathrm{F} / \mathrm{M}$ ratio 0.14 for parameters COD, BOD, TDS, TSS.

4. In $3^{\text {rd }}$ phase maximum removal efficiencies observed were $96.25 \%$, 97.84\%, 38.95\%, $87.97 \%$ for $\mathrm{F} / \mathrm{M}$ ratio 0.13 for parameters COD, BOD, TDS, TSS.

5. From this study, it was observed that for $\mathrm{F} / \mathrm{M}$ ratio 0.13 per day maximum removal efficiencies for parameters COD, BOD, TDS, TSS were achieved. Hence it can be concluded that performance of SBR can be enhanced by lowering $\mathrm{F} / \mathrm{M}$ ratio or by increasing MLSS concentration. It can also be enhanced by increasing react time and decreasing volume exchange ratio.

6. Average concentrations of outlet wastewater all three phases comply with the disposal standards by CPCB.

\section{REFERENCES}

Mehrotra, R., \& Trivedi, A. (2016). Study on characterisation of indian dairy wastewater. International Journal of Engineering Applied Sciences and Technology, 1(11), 77-88. 
Gürtekin E. (2014). Sequencing Batch Reactor in Industrial Wastewater Treatment: A Review. ISEM, Adiyaman, Turkey.

Mohseni-Bandpi, A., \& Bazari, H. (2004). Biological Treatment of Dairy Wastewater by Sequencing Batch Reactor. Iranian J Env Health Sci Eng, 1(2), 65-69.

Shete, B. S., \& Shinkar, N. P. (December, 2013). Dairy industry wastewater sources, characteristics \& its effects on environment. International Journal of Current Engineering and Technology, 3(5), 1611-1615.
Sutar, A. S., Mulla, R. K., \& Ranveer, A. C. (November, 2015). Effluent treatment plant of dairy wastewater - A performance evaluation. International Research Journal of Engineering and Technology, 2(8), 837-840.

David, M. K. (April, 2016). A review paper on Industrial Wastewater Treatment Processes. University of Nigeria, Nsukka. 